\title{
JURISPRUDÊNCIA ADMINISTRATIVA
}

\author{
ADVOCACIA GERAL DA UNIÃO - LEI COMPLEMENTAR N 73 - CRIAÇÃO \\ DE CARGOS
}

Interessado: Advogado-Geral da União

ASSUNTO: A Lei Complementar $n^{\circ} 73$, de 10 de fevereiro de 1993. Lei Orgânica da Advocacia-Geral da União - à análise de seu texto: as normas, do respectivo Título VII (Das Disposições Transitórias), que criam cargos públicos, sua natureza jurídica e a espécie normativa hábil às suas alteração e revogação.

$\left.{ }^{*}\right)$ Parecer $n^{\circ} \mathrm{GM}-023$

Adoto, para os fins do art. 41 da Lei Complementar $\mathrm{n}^{\circ} 73$, de 10 de fevereiro de 1993 , $o$ anexo PARECER $\mathrm{N}^{\circ}$ AGU/TH/01/2001, de 24 de maio de 2001, da lavra da Consultora da União, Dra. THEREZA HELENA S. DE MIRANDA LIMA, e submeto-o ao EXCELENTÍSSIMO SENHOR PRESIDENTE DA REPÚBLICA, para os efeitos do art. 40 da referida Lei Complementar.

Brasília, 29 de junho de 2001.

GILMAR FERREIRA MENDES

Advogado-Geral da União

(*) A respeito deste Parecer o Excelentíssimo Senhor Presidente da República exarou o seguinte despacho:

“Aprovo, 29.6.2001".

PARECERR N ${ }^{\circ}$ AGU/TH/01/2001 (Anexo ao Parecer GM-023)

ASSUNTO: A Lei Complementar $n^{\circ} 73$, de 10 de fevereiro de 1993 - Lei Orgânica da Advocacia-Geral da União - a análise de seu texto: as normas, do respectivo Título VII (Das Disposições Transitórias), que criam cargos públicos, sua natureza jurídica e a espécie normativa hábil às suas alteração e revogação.
EMENTA: As leis complementares, aspectos relevantes ao enfrentamento do tema posto: conceito, elemento material e formal; regime jurídico, distinção entre lei complementar e ordinária; leis complementares exaurientes e continuáveis, a relação destas últimas com a lei ordinária; o extravazamento. pela lei complementar, do âmbito material de validade, do campo material, que lhe fixou a Constituição, a natureza das normas resultantes desse extravazamento e a espécie normativa hábil às suas alteração e revogação. A Lei Complementar $n^{\circ} 73$, de 1993, o campo material que lhe fixou a Carta, em seu art. 131: a "organização" e o "funcionamento" da Advocacia-Geral da União, as "atividades de consultoria e assessoramento jurídico do Poder Executivo"; as normas, postas no seu texto, voltadas a criação de cargos públicos, matéria incluida pela Constituição no campo da lei ordinária, a natureza jurídica de tais normas, e a possibilidade de sua alteração e revogação pela legislação ordinária. A Lei Complementar $n^{\circ} 73$, sua classificação como continuável, e a respectiva extensão de normatividade pela legislação ordinária: a Medida Provisória $n^{\circ} 312$, suas sucessoras, e a Lei $n^{\circ}$ 8.682, de 1993. Conclusão. 


\section{PARECER}

\section{Senhor Advogado-Geral da União:}

Apresenta-se a Vossa Excelência, consoante determinado, estudo em que analisada a Lei Complementar $n^{\circ} 73$, de 1993 - Lei Orgânica da Advocacia-Geral da União -, no que concerne ao campo material a esta fixado pela Constituição e às disposições, vistas em seu Título VII (Das Disposiçōes Transitórias), as quais tratam da criação de cargos públicos, no fito de identificar a natureza dessas disposições e a espécie normativa hábil às suas alteração e revogação.

$\mathrm{Na}$ convicção de que, ao enfrentamento do tema posto a este trabalho, será útil relembrarem-se alguns aspectos relativos à figura normativa lei complementar, à guisa de introdução, pede-se vênia para trazê-los a seguir.

I-As leis complementares, aspectos relevantes ao enfrentamento do tema posto

\section{Conceito, elementos material e formal.}

A expressão lei complementar contém-se, hoje, no direito positivo brasileiro (C.F., arts. 59, II e 69). Ter-se-á, então, o conceito atual dessa figura normativa, nos termos em que encontrado na lição dos doutos:

"Lei Complementar

É espécie normativa infraconstitucional, destinada a desenvolver a normatividade de determinados preceitos constitucionais, dotada de matéria própria e sujeita a aprovação especial pelo Congresso Nacional. Distinguese dos demais atos normativos por meio de dois elementos que a qualificam: a) elemento maerial (campo próprio de incidência); e b) elemento formal (exigência de maioria absoluta para a sua aprovação)." (José Celso de Mello Filho, "Constituição Federal Anotada”, Saraiva, 1986, pág. 203. Destaques do original.)

"Lei Complementar é, pois, toda aquela que contempla uma matéria a ela entregue de forma exclusiva e que, em conseqüencia, repele normações heterogêneas, aprovada mediante um quorum próprio de maioria absoluta.
A lei complementar tem, por conseguinte, matéria própria - o que significa que recebe para tratamento normativo um campo determinado de atuação da ordem jurídica e só dentro deste ela é validamente exercitável matéria essa perfeitamente cindível ou separável da versada pelas demais normações, principalmente pela legislação ordinária.

Porém, a só consideração da matéria própria a ser contemplada pela lei complementar não nos leva ao conceito formal de lei complementar (conceito juridico-positivo), $e$, portanto, não nos fornece os elementos necessários para diferenciá-la, por exemplo, do decreto legislativo, da resolução, da lei delegada e mesmo da legislação ordinária ao nível do Estado-Membro e Município, haja vista que todos essas figuras legislativas têm, também, matérias próprias, campos distintos de atuação. Faz-se necessário, para caracterizarmos o regime peculiar a que está subordinada essa expressão normativa, que lancemos mãos do art. 69 da Lei Maior e dele extraiamos a exigência do 'quorum' especial de votação, em função do qual terá o projeto de lei complementar de obter para aprovação, no mínimo, a maioria absoluta dos votos dos membros das duas Casas Legislativas que formam o Congresso Nacional.

Congraçando-se esses dois elementos fundamentais, alcançamos a caracterização da lei complementar (espécie normativa autônoma) e sua definitiva indivudalização em face das demais espécies normativas, 'conduzidos a tanto por via de interpretação sistemática da Constituição, a partir dos seus arts. 59, II, e 69, passando pelos demais dispositivos que contemplem essa figura normativa'." (Celso Ribeiro Bastos, "Lei Complementar - Teoria e Comentários", Celso Bastos Editor, 1999, págs. 47 a 50. Do autor, os grifos; sublinhou-se.)

Identifica-se, pois, um ato legislativo como lei complementar, quando, ademais de expressamente prevista, esta, na Constituição, no ato em análise estejam reunidos os dois elementos destacados supra: o material, consubstanciado na matéria, no campo material em cada hipótese à lei complementar conferido, fixado, pela Carta, com exclusividade, 
para tratamento normativo; e a formal, consubstanciado no quorum próprio, peculiar, que lhe impõe a Lei Maior.

Ainda sobre os elementos essenciais, identificadores, da lei complementar, crê-se útil trazer, especificamente sobre aquele material - tão próximo ao tema deste trabalho - a palavra da doutrina e, a final, por sua magna importância, a lição de nossa Corte Suprema.

Colhe-se, a propósito, na doutrina:

"Matéria das leis complementares. Problema que surge no estudo da lei complementar é o saber se tem, ou não, matéria própria. Em outras palavras, se poderá ser dado o caráter de lei complementar à lei sobre qualquer matéria, apenas em decorrência de sua aprovação pelo procedimento fixado na Constituição para a elaboração de leis complementares. Ou se a edição de lei de natureza complementar somente cabe nos casos em que a Constituição expressamente o prevê.

Poder-se-ia pretender que não. Sendo toda e qualquer lei uma complementação da Constituição, na medida em que dispõe onde e segundo esta consentiu, a complementaridade decorreria simplesmente de um elemento formal objetivo: a sua aprovação pelo rito previsto na Constituição para esse tertium genus. Assim, seria complementar e, portanto, superior à lei ordinária, à lei delegada e ao decreto-lei, toda e qualquer lei que houvesse sido proposta como lei complementar e aprovada pela maioria absoluta em ambas as Casas do Congresso Nacional.

Essa interpretação, porém, é incorreta.

Rejeita-a o direito comparado. Analisando o art. 46 da Constituição francesa de 1958, afirma Georges Vedel: “A definição das leis orgânicas é extremamente simples: são leis orgânicas as leis às quais a Constituição confere essa qualidade" (Cours de droit constitutionnel et institutions politiques, p. 996).

Reprova-a o bom-senso. Criando um 'tertium genus', o constituinte o fez tendo um objetivo preciso; resguardar certas matérias de caráter paraconstitucional contra mudanças constantes e apressadas, sem, todavia, lhes imprimir rigidez tal que impeça sua modificação logo que necessário. Se assim foi motivado, não pretendeu evidentemente deixar ao arbítrio do legislador o decidir sobre o que deve ou o que não deve contar com esse grau particular de estabilidade.

Em conclusão, só nos casos previstos expressamente na Constituição cabe lei complementar 'stricto sensu'. É esse o entender de Nelson de Souza Sampaio (O processo legislativo, p. 39), de Geraldo Ataliba (Lei Complementar na Constituição, p.31) de entre outros, como o que já sustentávamos em 1968 (Do processo legislativo, cit., $\mathrm{n}^{\circ} 157$ ).

Não se olvide que a matéria de lei complementar é indelegável (v., supra, art. 68, $\left.\S 1^{\circ}\right)$." (Manoel Gonçalves Ferreira Filho, "Comentários à Constituição Brasileira de 1988", Vol. 2, pág. 124. Os grifos são do original.)

E preleciona, em v. acórdão, o SUPREMO TRIBUNAL FEDERAL, ao acolher, a unanimidade, na Sessão Plenária de 29 de agosto de 1996, Voto do Exmo. Sr. Ministro Carlos Velloso. Voto em que S.Exa., tendo presente a essencialidade do elemento material da lei complementar, analisou aquele fixado no art. 192, IV, da Constituição, e sob os limites deste considerando a Lei $n^{\circ} 4.595$, de 1964 , argumentou e concluiu que:

“Dir-se-á que a Constituição terá recebido a Lei 4.595, de 1964, como lei complementar. E que, cuidando ela do regime jurídico do pessoal do Banco Central - art. 52 - somente lei complementar poderia alterá-lo, pelo que não teria aplicação, no caso, a Lei 8.112/90.

Em linha de princípio, é correta a afirmativa.

No que toca à 'organização', o 'funcionamento' e 'as atribuições' do Banco Central, as normas constantes da Lei 4.595, de 1964, têm 'status' de lei complementar.

No que diz respeito, entretanto, 'ao pessoal' do Banco Central, assim não ocorre, dado que essa matéria não se inclui naquelas postas expressamente, no inciso IV do art. $192 \mathrm{da}$ Constituição..."

Registrando, no ponto:

"São oportunas as lições do saudoso Geraldo Ataliba e José Souto Maior Borges, no sentido de que a lei complementar tem limites de forma e de fundo. Quanto aos limites de fundo, "nāo pode regular senāo matéria de- 
limitadas prévia e exaustivamente pela Constituição" ("Lei Complementar Tributária", 1975, pág. 54/55; Geraldo Ataliba, "Lei Complementar na Constituição", 1971, pág. 58)" (ADIN n ${ }^{\circ} 449-\mathrm{DF}$ : voto do Relator. In D.J. de 22.11.96. Destaques do original; acresceram-se sublinhas.)

2) Regime jurídico, distinção entre lei complementar e ordinária.

Relativamente ao regime jurídico próprio às leis complementares, ao seu regime jurídico formal e àquele material, e a ser, dito regime jurídico próprio, o verdadeiro traço de distinção entre a lei complementar e a lei ordinária, tem-se a clara, precisa, lição de Souto Maior Borges, quando assim disserta:

“ $\$$ 5. Regime jurídico da lei complementar

Sem que sejam conjugados dois requisitos constitucionais - quorum especial e qualificado - mais o âmbito material de competência legislativa próprio - não há lei complementar no direito constitucional brasileiro. Haverá, quando muito, lei ordinária da União (observância do quorum e inobservância do âmbito material de validade da lei complementar, contido não obstante o ato legislativo dentro do campo da lei ordinária da Uniāo) ou lei complementar material, viciada por inconstitucionalidade formal ou extrínseca (inobservância do quorum e observância do âmbito material de cabimento da lei complementar). Donde se conclui que, extrapolando o seu campo material próprio - se observado no entanto o campo de atribuiçōes legislativas da União - a lei não será formalmente complementar, mas ordinária. Inobservado, ao contrário, o quorum especial e qualificado, mesmo se respeitada a competência material da União, a lei "complementar" será inconstitucional.

A lei complementar disciplinada pela Constituição é a lei complementar no sentido formal e material.

A especificidade da lei complementar pode ser identificada no seu regime jurídico formal, único exclusivo e próprio da espécie, em contraste com a lei ordinária, eis que o 'quorum' de aprovação da lei complementar é superior ao exigido para a lei ordinária, aliado ao seu regime juridico material, relacionado com as matérias que constituem o objeto de regulação mediante lei complementar. $O$ regime juridico material da lei complementar será estudado a seguir (neste Cap., § 7).

É o critério formal e material adotado pela Constituição que dá a unidade de regime à lei complementar, sem o que não se legitimaria o seu estudo como uma categoria científica autônoma.

$O$ regime jurídico material, que é revelado pela análise das diversas hipóteses especificas de cabimento da lei complementar contempladas pelo direito positivo brasileiro e o 'quorum' previsto no art. 50 da Constituição fornecem os atributos específicos que a distinguem dos demais atos legislativos.

Consequientemente, o único critério, rigorosa e dogmaticamente jurídico para estabelecer uma distinção válida entre lei complementar e lei ordinária reside na diversidade do regime jurídico, decorrente de um específico processo de elaboração legislativa, e âmbito material de validade peculiar. Eo regime jurídico diverso - e só ele - que as distingue conceitualmente. A lei complementar é a resultante de um procedimento legislativo vinculado a critérios constitucionais de direito formal (e.g., o quorum de votação) e de ordem material ou de direito substantivo (a matéria correspondente a uma fatia do campo global distribuido rigidamente segundo esquemas constitucionais de competência legislativa).

Lei complementar é o ato legislativo para cuja elaboração a Constituição Federal exige o 'quorum' especial do art. 50. À luz do regime jurídico formal estabelecido pela Constituição no disciplinamento dessas competências legislativas e apenas sob esse ângulo, o 'quorum' do art. 50 - requisito de existência e validade - fornece a diferença específica da lei complementar em contraste não só com a lei ordinária, mas também com as outras categorias legislativas. É esse 'quorum' atributo que, ao acrescentar-se ao gênero "atos normativos" forma a espécies daquele mesmo gênero. Todavia, apenas ele não basta, porque a Constituição o associa à indeclinável exigência de inserção do ato legislativo num âm- 
bito material de validade próprio. Se o critério jurídico formal, por si só, fosse suficiente para a identificação da lei complementar, qualquer lei editada pela União com a observância do 'quorum' previsto no art. 50 converter-se-ia 'ipso facto' em lei complementar, o que não ocorre.

Como se expôs, o 'quorum' de aprovação é um requisito para a formação que, aliado à matéria privativa da lei complementar, resulta em ato legislativo elaborado com observância plena dos cânones da Constituição." ("Lei Complementar Tributária", RT, 1975, págs. 72/73. Grifos do autor, e acrescidos.)

$\mathrm{Da}$ lição transcrita, valem destacados alguns de seus ensinamentos. Por exemplo, o de que: inobservado, e só, o quorum exigido pela Constituição (obedecido, frise-se, o âmbito material fixado à lei complementar), terse-á "lei complementar material", conquanto viciada, esta, por inconstitucionalidade (inconstitucionalidade formal, extrínseca); diferentemente, se inobservado o âmbito material de validade da lei complementar, e só este (obedecida, anote-se, a exigência de 'quorum' específico), não se terá lei complementar. Nessa última hipótese, poder-se-á ter lei ordinária, caso $o$ ato legislativo se contenha no campo material fixado, pela Constituição, à lei ordinária federal.

Mais: a distinção entre as figuras normativas lei complementar e lei ordinária deflui dos respectivos, e distintos, regimes jurídicos, cada um destes a contemplar um determinado processo de elaboração legislativa e um peculiar âmbito material de validade.

3) Leis complementares exaurientes e continuáveis, a relação destas últimas com a lei ordinária.

Tem-se buscado, neste trabalho, rememorar, do contexto jurídico relativo às leis complementares, os aspectos que melhor instruam o tema que the foi posto: a análise da Lei Complementar $n^{\circ} 73$, de 1993, do enfoque antes apontado.

Nesse mister, vê-se cabível trazer à balha, aqui agora, a classificação da leis complemen- tares em exaurientes e continuáveis, conferindo-se destaque às últimas e à sua relação com a lei ordinária.

$\mathrm{E}$, mais uma vez objetivando lembrança a que asseguradas clareza e precisão, traz-se a palavra de nossa melhor doutrina:

\section{"2.1. LEIS COMPLEMENTARES EXAU.} RIENTES E CONTINUÁVEIS

Desde logo cumpre distinguir-se entre dois tipos de leis complementares que denominaremos de exaurientes e continuáveis. Expliquemos em que consiste tal distinção.

As leis complementares exaurientes são aquelas que incidem de maneira direta sobre os fatos ou comportamentos regulados. Por se tratarem de normas cheias, maciças, prescindem de qualquer normação complementar. Essas leis contêm uma manifestação jurídica que não se compõe de qualquer outro manifestar regratório secundário

O mesmo não se dá, no entanto, com as leis que denominamos continuáveis. Nestas, o recorte da sua matéria se dá dentro de um tecido normativo mais amplo. Em linguagem figurada seria como, com a ajuda de uma tesoura, abrir um buraco na superfície de um pedaço de tecido. Dessa operação resultaria, como é óbvio, o seguinte: o pedaço destacado e o restante do material. A lei complementar seria a parcela retirada e a lei ordinária, o pano envolvente. É possível dizer que as leis complementares continuáveis são aquelas normas que permitem a existência de outras espécies normativas, simultaneamente. Há uma extensão de sua normatividade por intermédio de uma lei ordinária.

Na lei complementar continuável a formulação jurídica efetivamente emitida fica aquém do seu propósito. $O$ teor da normação complementar continuável é por si só insuficiente para abranger todas as especificidades da matéria que versa, portanto ela necessita de uma outra norma para complementá-la. Resta dizer que as normas complementares continuáveis se caracterizam por demandarem um aditamento à sua área e regulação, que é feito neste caso pela lei ordinária." 
(Celso R. Bastos, ob. cit., págs. 93 e 95. Destaques do autor, e acrescidos.)

Tem-se, pois, como lei complementar continuável, aquela que - pela circunstância de o teor de sua normação ser, por si só, insuficiente para abranger todas as especificidades da matéria que é objeto da lei — demanda um aditamento, este efetivado por lei ordinária. Há, então, atinentemente à lei complementar continuável, "uma extensão de sua normatividade", mediante uma "lei ordinária".

4. O extravazamento, pela lei complementar, do âmbito material de validade, do campo material, que lhe fixou a Constituição, a natureza das normas resultantes desse extravazamento e a espécie normativa hábil às suas alteração e revogação

Viu-se que a lei complementar tem, como seu elemento essencial, o campo material (a matéria) que lhe é fixado pela Constituição. Retro, sob 2, anotou-se que, inobservado esse âmbito material de validade, em seu todo, sequer se terá lei complementar; poder-se-á ter, na hipótese, lei ordinária, caso o ato legislativo e contenha no campo reservado à lei ordinária.

Tem-se agora em mira a hipótese em que a lei complementar válida, eficaz (observados seus elementos formal e material) haja, incidentalmente, extravazado o respectivo campo material, e, de resultado, contenha normas a disciplinarem matérias que não são próprias, específicas, de seu campo material. E, a propósito, indaga-se: quais as consequiências desse extravazamento? Qual a natureza jurídica de tais normas?

Respondem-nos o saudoso Geraldo Ataliba, e Celso Bastos:

“... 'Nada obsta' a que a lei complementar discipline matéria própria de outras normas, salvo a resolução e o decreto-legislativo. Desde que se trate de matéria de competência do Congresso, nada impede que a lei complementar a reja. 'Mesmo porque, quem pode o mais pode o menos'.

Os reparos que se podem formular são meramente formais, não atingindo o mérito da questão. Comprometer-se-ia, com isto, a boa técnica legislativa, mas não a eficácia da norma...

1. Derrogação de lei complementar por lei ordinária

Acontecendo de a lei complementar extravasar o campo específico próprio da espécie - e o problema se coloca principalmente com relação à lei ordinária - surge a questão de se saber se, nesta hipótese, pode ser derrogada por norma que não outra lei complementar.

Em outras palavras: pode, por exemplo, a lei ordinária dispor em contrário à lei complementar, em matéria não privativa desta?

A resposta é intuitiva e decorre das imposições do sistema: $\operatorname{sim}$. A lei ordinária pode perfeitamente dispor sobre qualquer matéria não reservada à lei complementar, inclusive derrogando a espécie normativa, neste campo.

É que a lei complementar, fora de seu campo específico - que é aquele expressamente estabelecido pelo constituinte - nada mais é do que lei ordinária. A natureza das normas jurídicas - em sistemas positivos como o nosso, objeto de quase exaustivo tratamento constitucional - é dada conjuntamente pela forma (no caso, de elaboração) e pelo conteúdo. Este sem aquela não configura a entidade, da mesma maneira que aquela sem este. Só há lei complementar válida e eficaz, quando concorrem os dois elementos citados para configurá-la.

Faltando qualquer deles, não se tem a espécie. Na ausência da forma, não há lei complementar, nem nada. É nulo o ato. É nenhum.

$\mathrm{Na}$ falta de conteúdo o ato é existente, é válido, é norma mas não tem a eficácia própria da espécie: é mera lei ordinária.

Sem o concurso de matéria e forma não se configura a entidade. Não chega a reunir os elementos que lhe dão como tal.

2. Extravasão incidental de matéria própria de lei complementar

Pode acontecer de a lei complementar, incidentalmente, ditar regra em matéria não própria e específica do seu campo. Pode o legislador entender oportuno, conveniente ou necessário complementar certas figuras, institutos ou mesmo a disciplina de certas situa- 
ções, com a edição de normas não próprias da lei complementar.

Então, teríamos um ou alguns artigos ou parágrafos, inseridos no texto da lei complementar, os quais entretanto seriam, em rigor técnico e para efeitos exegéticos, lei ordinária - desta natureza dotados tais mandamentos, por força do sistema.

Colocada a hipótese - que nada tem de cerebrina - cabe indagar: São aplicáveis a estes mandamentos os critérios fixados anteriormente para textos legais inteiros de lei complementar, ou unidades distintas, inseridas em lei complementar, versando matéria de lei ordinária?...

Este exemplo - como outros do mesmo gênero - enseja ver que, excedendo a lei complementar a própria esfera de competência, nada mais é do que lei ordinária, passível de trata jurídico idêntico ao próprio desta espécie, ingegralmente." (GEALDO ATALIBA, "Lei Complementar na Constituição", RT, 1971, fls. 35 a 38. Grifos do autor; sublinhouse.)

"Outro aspecto relevante da lei complementar frente às demais espécies normativas diz respeito ao seu relacionamento com a lei ordinária, quando lei complementar resolve dispor sobre matéria de lei ordinária. É sabido que a reserva de matéria disposta na Constituição à lei complementar, não proíbe, que regule ela, matérias que estejam fora do seu âmbito reservado. Quando a lei complementar versa matérias de lei ordinária, é dizer, invade a área de competência da lei ordinária, ao contrário do que se pensa não se está de um caso de nulidade. Apenas, nesse caso, deve se considerar a lei complementar como mera lei ordinária. Daí se extrai que essa "pseudo" lei complementar pode ser revogada por lei ordinária, dispensando desta maneira a necessidade de votação por maioria absoluta. Seguindo essa linha de raciocínio fica claro que a lei ordinária posterior que verse sobre a matéria da "pseudo" lei complementar em questão, substitui a lei complementar no que conflitarem.

Em suma, no caso de lei complementar versar matéria de lei ordinária, resta claro dizer que ela pode ser revogada sem a necessidade de votação por maioria absoluta, ou seja pode ela ser revogada por meio da edição de lei ordinária. Vale dizer, também, que no caso, o fato da lei ter atingido um quorum próprio de lei complementar, não é elemento suficiente para caracterizá-la como tal, pois falta a ela a matéria própria destinada pela Constituição. Houve sim aprovação do quorum além do normalmente necessário, o que não pode trazer malefício algum a lei, que continua sendo uma mera lei ordinária.

Quando a lei complementar invadir a área de competência da lei ordinária, frisamos, não estamos diante de uma nulidade; apenas a lei complementar deve ser considerada como lei ordinária. Desta maneira pode ser ela revogada sem a necessidade de votação por maioria absoluta, ou seja quorum qualificado. A le $i$ ordinária posterior que verse sobre a mesma matéria, tem o condão de substituir a lei complementar existente naquilo que conflitarem." (Celso Bastos, ob. cit., págs. 143 e 144; grifou-se.)

$\mathrm{E}$, das lições transcritas, facilmente se infere que, na hipótese de uma lei complementar válida, eficaz no trato da matéria que lhe fixou a Constituição, extravazar, em alguns de seus passos, esse âmbito material, e tratar de matéria outra, que a Carta atribua à lei ordinária, invadindo, pois, o campo da lei ordinária, a consequiência dos aludidos extravazamento e invasão será a de qualificar-se, no ponto, a lei complementar, como lei ordinária. E, por $5 \mathrm{~b}$ vio, as normas resultantes serão normas ordinárias, passíveis de alteração, e revogação, pela legislação ordinária.

Ainda sobre a hipótese ora em foco, e para bem finalizar sua análise, cabe trazer-se a palavra de Souto Maior Borges, quando - após realçar que "os campos da lei complementar e da lei ordinária, em princípio, não se interprenetram, numa decorrência da técnica constitucional de distribuição "ratione materiae" de competência legislativa" - preleciona:

"Não se coloca o problema da revogação das leis quando estamos diante de campos legislativos distintos. Se a lei ordinária invadir o campo da lei complementar será, por isso mesmo, inválida, independendo de revogação. Do mesmo modo, a inobservância do 'quorum' especial e qualificado e a extravasão do seu âmbito material de validez não 
possibilitam sequer o aperfeiçoamento existencial de ato legislativo, como lei complementar.

14. Com efeito, a interpretação inconstitucional dos campos privativos de legislação pode-se dar em diversas hipóteses: a) a lei complementar invade o campo reservado às simples leis ordinárias da União; b) a lei ordinária da União invade o campo da lei complementar; c) a lei complementar invade o campo da legislação ordinária dos Estadosmembros e Municípios; d) a lei ordinária dos Estados-membros e Municípios invade o campo da lei complementar.

Distintas as hipóteses, diversas serão as conseqüências jurídicas de cada uma.

Se a lei complementar (a) invadir o âmbito material de validez da legislação ordinária da União, valerá tanto quanto uma lei ordinária. Sobre esse ponto, não há discrepância na doutrina. A lei complementar fora do seu campo específico, cujos limites estão fixados na Constituição, é simples lei ordinária. Sem a congregação dos dois requisitos estabelecidos pelo art. 50 da Constituição, o quorum especial e qualificado (requisito de forma) e a matéria constitucionalmente prevista como objeto de lei complementar (requisito de fundo), não há lei complementar. Contudo, se não ultrapassar a esfera de atribuições da União, o ato legislativo será existente, válido e eficaz. Só que não estará submetido ao regime jurídico da lei complementar — inclusive quanto à relativa rigidez - mas ao da lei ordinária, podendo conseqüentemente ser revogado por esta.

Em todas essas hipóteses, não se coloca o problema da revogação da lei complementar por lei ordinária ou vice-versa." ("Eficácia e Hierarquia da Lei Complementar", in RDP n ${ }^{\circ}$ 25, Ano VI, pág. 98. Acresceram-se sublinhas.)

II - A Lei Complementar $n^{\circ} 73$, de 1973, o campo material que lhe fixou a Carta, em seu art. 131: a "organização" e o "funcionamento" da Advocacia-Geral da Uniāo, as "atividades de consultoria e assessoramento jurídico do Poder Executivo"; as normas, postas no seu texto, voltadas à criação de cargos públicos, matéria incluída pela Cons- tituição no campo da lei ordinária, a natureza jurídica de tais normas, e a possibilidade de suas alteração e revogação pela legislação ordinária. A Lei Complementar $n^{\circ} 73$, sua classificação como continuável, e a respectiva extensão de normatividade pela legislação ordinária: a Medida Provisória $n^{\circ} 312$, suas sucessoras, e a Lei $n^{\circ} 8.682$, de 1993.

1. O campo material fixado, à Lei Complementar $n^{\circ} 73$, de 1993, pelo art. 131 da Constituição. $O$ art. 29 do ADCT de 1988.

Dita, no ponto, a Carta:

"Art. 131. A Advocacia-geral da União é a instituição que, diretamente ou através de órgão vinculado, representa a União, judicial e extrajudicialmente, cabendo-lhe, nos termos da lei complementar que dispuser sobre sua organização e funcionamento, as atividades de consultoria e assessoramento jurídico do Poder Executivo.

$\S 1^{\circ}$ A Advocacia-Geral da União tem por chefe o Advogado-Geral da União, de livre nomeação pelo Presidente da República dentre cidadãos maiores de trinta e cinco anos, de notável saber jurídico e reputação ilibada.

$\S 2^{\circ} \mathrm{O}$ ingresso nas classes iniciais das carreiras da instituição de que trata este artigo far-se-á mediante concurso público de provas e títulos.

$\S 3^{\circ} \mathrm{Na}$ execução da dívida ativa de natureza tributária, a representação da União cabe à Procuradoria-Geral da Fazenda Nacional, observado o disposto em lei.:

Extraiam-se, da transcrita disposição constitucional, porque relevantes ao tema deste trabalho, os seguintes passos; contém previsão, expressa, de lei complementar; atribui, a tal lei complementar, o tratamento normativo da organização e do funcionamento da Advocacia-Geral da União; confere, à lei complementar em foco, estabelecer os termos em que irão ser desempenhadas, pela Instituição, as atividades de consultoria e assessoramento jurídico do Poder Executivo.

$E$, isto feito, registre-se que, no âmbito constitucionalmente gizado à Lei Orgânica da Advocacia-Geral da União se incluem as seguintes matérias: a organização, e o funcionamento, da $\mathrm{AGU}$; o desempenho, pela $\mathrm{AGU}$, 
das atividades de consultolria e assessoramento jurídico do Poder Executivo. Esse o campo material fixado à lei complementar de que trata o art. 131 da Constituição.

Aludido campo material, reiterou-se o art. 29 do ADCT/1988, verbis:

“Art. 29. Enquanto não aprovadas as leis complementares relativas ao Ministério Público e à Advocacia-Geral da União, o Ministério Público Federal, a Procurdoria-Geral da Fazenda Nacional, as Consultorias Jurídicas dos Ministérios, as Procuradorias e Departamentos Jurídicos de autarquias federais com representação própria e os membros das Procuradorias das universidades fundacionais públicas continuarão a exercer suas atividades na área das respectivas atribuições.

$\S 1^{\circ} O$ Presidente da República, no prazo de cento e vinte dias, encaminhará ao Congresso Naconal projeto de lei complementar dispondo sobre o organização e o funcionamento da Advocacia-Geral da União.

$\S 2^{\circ}$ Aos atuais Procuradores da República, nos termos da lei complementar, será facultada a opção, de forma irretratável, entre as carreiras do Ministério Público Federal e da Advocacia-Geral da União.

$\S 3^{\circ}$ Poderá optar pelo regime anterior, no que respeita as garantias e vantagens, $o$ membro do Ministério Público admitido antes da promulgação da Constituição, observando-se, quanto às vedações, a situação jurídica na data desta.

$\S 4^{\circ}$ Os atuais integrantes do quadro suplementar dos Ministérios Públicos do Trabalho e Militar que tenham adquirido estabilidade nessas funções passam a integrar o quadro da respectiva carreira.

$\S 5^{\circ}$ Cabe à atual Procuradoria-Geral da Fazenda Nacional, diretamente ou por delegação, que pode ser ao Ministério Público estadual, representar judicialmente a União nas causas de natureza fiscal, na área da respectiva competência, até a promulgação das leis complementares previstas neste artigo."

2. As normas, postas no texto da Lei Orgânica da Advocacia-Geral da Uniāo, voltadas à criação de cargos públicos, matéria incluída pela Constituição no campo material da lei ordinária: a natureza jurídica de tais nor- mas, e a possibilidade de sua alteração, ou revogação, pela legislação ordinária.

Na primeira parte deste trabalho, esteve em foco a hipótese na qual lei complementar, incidentalmente, extravaze o seu âmbito material, e disponha sobre matéria que a Carta atribui à lei ordinária. E se registrou que, em tal hipótese, as normas resultantes desse extravazamento seriam normas de natureza ordinária, e, pois, passíveis de alteração, e de revogação, pela legislação ordinária (lei ordinária; ou medida provisória, consoante previsto no art. 62 da Lei Maior).

Isto posto, cabe anotar-se que a Lei Complementar $n^{\circ} 73$, de 1993, em seu Título VII - Das Disposições Transitórias, dispôs sobre a criação de cargos, ditando, por exemplo:

"Art. 55. São criados, com natureza especial, os cargos de Procurador-Geral da União, Procurador-Geral da Fazenda Nacional, Consultor-Geral da União e de Corregedor-Geral da Advocacia da União, privativos de Bacharel em Direito, de elevado saber jurídico e reconhecida idoneidade, com dez anos de prática forense e maior de trinta e cinco anos."

“Art. 57. São criados os cargos de Secretário-Geral de Contencioso e de Secretário-Geral de Consultoria, de natureza especial, privativos de Bacharel em Direito que reúna as condições estabelecidas no art. 55 desta lei complementar."

A criação de cargos públicos (suas transformação a extinção), como sabido, é matéria atribuída pela Constituição à lei ordinária, nos seguintes termos:

"Art. 48. Cabe ao Congresso Nacional, com a sanção do Presidente da República, não exigida esta para o especificado nos arts. 49, 51 e 52, dispor sobre todas as matérias de competência da União, especialmente sobre:

$X$ - criação, transformação e extinção de cargos, empregos e funções públicas;

Ergo, a Lei Complementar $n^{\circ} 73$, de 1993, ao dispor sobre a criação de cargos públicos, extravazou o seu âmbito próprio, invadindo o campo da lei ordinária. De consequência, as normas desse extravazamento resultantes são 
normas ordinárias, passíveis de alteração, ou revogação, pela legislação ordinária. Normas válidas, eficazes, mas de natureza ordinária.

\section{A Lei Complementar $n^{\circ} 73$, sua classifi-} cação como continuável, e a respectiva extensão de normatividade pela legislação ordinária: a Medida Provisória $n^{\circ} 312$, suas sucessoras, e a Lei $n^{\circ} 8.682$, de 1993.

Analisando, especificamente, o art. 131 da Constituição e a Lei Complementar $n^{\circ} 73$, de 1993, Celso Bastos assere que esta pode ser classificada como "lei complementar integrativa e continuável, já que ela não possui o condão de produzir todos os seus efeitos de imediato", e acresce: "vale dizer que a lei complementar em estudo não estabelece prérequisitos para elaboração de lei ordinária ou qualquer outra espécie normativa." (ob. cit., pág. 219. Grifou-se.)

Cabe lembrado, então, que neste trabalho se focalizou a lei complementar dita continuável, sua caracteristica de demandar "um aditamento à sua área de regulação", aditamento este a ser efetivado pela legislação ordinária, registrando-se a "extensão de sua normatividade por intermédio de uma lei ordinária" (v. fls. 6)

Precisa, portanto, a classificação dada or Celso Bastos à Lei Complementar $n^{\circ} 73$, de 1993: as especificidades, múltiplas, das matérias incluías no seu âmbito - como, v.g., a criação dos cargos de confiança a serem ocupados pelos titulares dos órgãos da $\mathrm{AGU}$, a fixação da respectiva remuneração - induvidosamente a caracterizam como lei complementar continuável, a demandar (quanto às aludidas especificidades) aditamento em lei ordinária.

Essa qualificação, ademais, refletiu-a a realidade: vigente a Lei Complementar $n^{\circ} 73$, de seguida fez-se indispensável, por exemplo, criar os cargos de Procurador Regional (na organização da AGU, previstas cinco Procuradorias Regionais da União) e alterar a denominação dos carges de Consultor da República (transformando-os em de Consultor da União). Essas especificidades, atendeu-as a Medida Provisória $n^{\circ}$ 312, de 11 de fevereiro de 1993, que, sucedida pelas de n's 314,316 , 321 e 325 , ensejou adviesse a Lei $n^{\circ} 8.682$, de 14 de julho de 1993.

A hipótese versada, aliás, não é singular. A Lei Complementar $n^{\circ} 75$, de 20 de maio de 1993, a qual “dispõe sobre a organização, as atribuições e o estatuto do Ministério Público da União" (C.F., art. $\left.128, \S 5^{\circ}\right)$, teve, recentemente, diga-se assim, aditamento por lei ordinária: adveio, em 24 de outubro de 2000, a Lei $n^{\circ} 10.033$, pela qual "criados trezentos e quatro cargos de procurador da República na carreira do Ministério Público Federal", a serem "providos por nomeação, mediante concurso público, nos termos do inciso II do art. 93 da Constituição Federal e da Lei Complementar $n^{\circ} 75$, de 20 de maio de 1993". (V., na Lei Complementar $n^{\circ} 75$, p. ex., seus arts. 268 e 269.)

\section{Conclusão.}

A Lei Complementar $\mathrm{n}^{\circ} 73$, de $1993-\mathrm{Lei}$ Orgânica da Advocacia-Geral da Uniāo tem campo material próprio, que lhe é fixado pela Constituição (art. 131). Entretanto, a análise do seu texto evidencia que este contém normas a disciplinarem matéria estranha àquele campo material, matéria atribuída, pela Carta, à legislação ordinária.

Ao extravazar, incidentalmente, o seu âmbito material específico, nisso invadindo a área de competência da lei ordinária, a L.C. $n^{\circ} 73$ há de ser considerada lei ordinária. As normas resultantes desse extravazamento são normas ordinárias. Logo, passíveis de alteração e revogação, pela legislação ordinária (lei ordinária, ou medida provisória).

Dentre as normas ordinárias encontradas no corpo da Lei Complementar $n^{\circ} 73$, estão aquelas que tratam da criação de cargos, matéria esta atribuída, pela Carta, à lei ordinária (cf. art. 48, X). Normas válidas, eficazes, mas de natureza ordinária, cujas alteração e revogação, reitere-se, cabem à legislação ordinária.

Sub censura.

Brasília, 24 de maio de 2001.

Thereza Helena S. de Miranda Lima, Consultora da União 